\title{
Cholesterol-lowering effect of soyabean lecithin in normolipidaemic rats by stimulation of biliary lipid secretion
}

\author{
BY ELISABETH POLICHETTI ${ }^{1}$, NICOLAS DIACONESCU ${ }^{\mathbf{1}}$, \\ PAULETTE LECHENE DE LA PORTE 1 , LINA MALLI', HENRI PORTUGAL ${ }^{2}$, \\ ANNE-MARIE PAULI ${ }^{2}$, HUGUETTE LAFONT ${ }^{1}$, BEATRIZ TUCHWEBER ${ }^{4}$, \\ IBRAHIM YOUSEF ${ }^{3}$ AND FRANÇOISE CHANUSSOT ${ }^{*}$ \\ ${ }^{1}$ INSERM U130 and ${ }^{2}$ Laboratoire Central, Hôpital Sainte Marguerite, 13009 Marseille, France \\ ${ }^{3}$ Department of Nutrition and ${ }^{4}$ Department of Pharmacology, University of Montreal, Montreal, \\ H3C 3J7, Canada
}

(Received 19 January 1995 - Revised 16 June 1995 - Accepted 27 June 1995)

\begin{abstract}
The purpose of the present study was to assess the role of the liver in the plasma-cholesterol-lowering effect of soyabean lecithin. Normolipidaemic rats were fed on lecithin-enriched or control diets with the same amount of protein. The lecithin diets contained $200 \mathrm{~g} / \mathrm{kg}$ high-fat commercial semi-purified soyabean lecithin ( $230 \mathrm{~g} / \mathrm{kg}$ total lipids as soyabean phosphatidylcholine) or $200 \mathrm{~g} / \mathrm{kg}$ high-fat purified soyabean lecithin $(930 \mathrm{~g} / \mathrm{kg}$ total lipids as soyabean phosphatidylcholine). The control diets were a lowfat diet $(40 \mathrm{~g} \mathrm{fat} / \mathrm{kg})$ and a high-fat triacylglycerol-rich diet $(200 \mathrm{~g} \mathrm{fat} / \mathrm{kg})$. The high-fat diets were isoenergetic. The cholesterol-lowering effect of the lecithin-enriched diets was associated with significantly lower levels of plasma total- and HDL-cholesterol and significantly higher levels of bile phosphatidylcholine (PC), bile salts and cholesterol. These findings suggest that the liver plays a major role in the reduction of plasma cholesterol, the increased biliary lipid being provided by both HDL and the hepatic microsomal pools of $\mathrm{PC}$ and cholesterol.
\end{abstract}

Soyabean lecithin: Cholesterol: Bile: Liver

Many studies have revealed that, in humans as well as in other species (i.e. rats), HDL are implicated in the process of bile lipid secretion (Halloran et al. 1978; Esnault-Dupuy et al. 1987; Rivabene et al. 1992) and that HDL, particularly $\mathrm{HDL}_{2}$, are a major source of biliary steroids (Bravo \& Cantafora, 1990). Furthermore, it has been demonstrated recently that an extrahepatic HDL-phosphatidylcholine (PC) pool is a major source of biliary PC (Chanussot et al. 1990; Portal et al. 1993). These observations have raised speculation concerning the metabolic effects of changes in HDL or HDL-like particles induced by administration of soyabean lecithin. Martins et al. (1989) and Williams et al. (1984) showed that a lecithin-rich diet could lead to a direct transfer of lecithin to plasma HDL or to the formation of HDL-like particles having a high potential of PC linkage.

The cholesterol-lowering effect of lecithin is not clearly established (Tompkins \& Parkin, 1980; Williams et al. 1984; Knuiman et al. 1989). It has been suggested that polyunsaturated lecithin lowers plasma cholesterol, possibly by enhancing HDL formation (Jimenez et al. 1990). In addition, a soyabean-lecithin-enriched diet was shown to increase bile lipid secretion (Rioux et al. 1994). Thus, the present study was carried out in order to determine if the cholesterol-lowering effect can be correlated to a stimulation of bile production by HDL or HDL-like particles in normolipidaemic rats fed on diets enriched with soyabean lecithin.

\footnotetext{
* For reprints
} 


\section{MATERIALS AND METHODS}

\section{Animals and diets}

Male Wistar rats (Iffa Credo, L'Arbresle, France) were kept in pairs for 2 weeks in an animal room under controlled conditions (temperature: $22^{\circ}$; light cycle: $07.00-19.00$ hours; humidity: $50 \%$ ). A standardized diet UAR AO4 (UAR, Epinay sur Orge, France) and tap water were supplied ad lib. Mean weight at the end of this baseline period was 292 (SE 9) g. The rats were divided into four groups receiving the following diets: control (C): low-fat diet $(40 \mathrm{~g}$ fat $/ \mathrm{kg}$ diet; $n$ 7); control-triacylglycerol (C-TG): high-fat diet containing sunflower-seed oil ( $200 \mathrm{~g}$ oil $/ \mathrm{kg}$ diet; $n 7$ ); semi-purified lecithin (NPLE): high-fat diet (200 g semi-purified lecithin/kg diet; $n$ 8); purified lecithin (PLE): high-fat diet ( $200 \mathrm{~g}$ lecithin/kg diet) containing pure soyabean lecithin $(n 6)$ (Table 1). The commercial semipurified lecithin contained $230 \mathrm{~g}$ pure soyabean $\mathrm{PC} / \mathrm{kg}$. The pure soyabean lecithin contained $930 \mathrm{~g}$ pure soyabean $\mathrm{PC} / \mathrm{kg}$.

The C, C-TG, NPLE and PLE diets in paste form were supplied ad lib. for 2 weeks. At the end of this period, mean weight gain was 38 ( $\mathrm{SE} 4$ ) $\mathrm{g}$ and there was no significant difference in weight gain between the four groups. Feed intake was similar in the four groups (18.5 (SE 2.0) g/d per rat). The three high-fat diets were chosen in order to be isoenergetic $(16.2,15.7$ and $15.6 \mathrm{~kJ} / \mathrm{g}$ for the C-TG, NPLE and PLE diets respectively). Thus, the rats in these three groups were given the same daily lipid energy intake, enabling the effects of the C-TG, NPLE and PLE diets to be compared in terms of triacylglycerol or phospholipid energy. Under such conditions the composition of fatty acids provided by the C-TG diet was different from that provided by the NPLE and PLE diets (Table 2). The C-TG diet did not contain linolenic acid whereas the NPLE and PLE diets were enriched in this fatty acid $(7 \mathrm{~g} / 100 \mathrm{~g}$ total fatty acids). Iwata et al. (1992) showed that such a difference $(7 \%)$ in dietary linolenic acid did not induce changes in plasma cholesterol levels of rats given safflower-seed lecithin or soyabean lecithin. Thus, it is the amounts of fatty acid in the form of triacylglycerols or lecithin that are implicated in cholesterolaemic changes rather than the composition of these fatty acids. The results of the C-TG, NPLE and PLE groups can, therefore, be compared.

\section{Experimental design}

After diet administration, rats previously feed-deprived overnight were anaesthetized at 08.00 hours by an intraperitoneal injection of $48 \mathrm{mg}$ pentobarbital sodium (Sanofi, Montpellier, France) $/ \mathrm{kg}$ body weight and placed under an infrared heating lamp to maintain a constant body temperature of $37^{\circ}$. The main bile duct was cannulated with a polyethylene PE-10 catheter (Clays-Adams, Parsippany, NJ, USA) and bile was recovered in $15 \mathrm{~min}$ fractions for $2 \mathrm{~h}$. After the first $15 \mathrm{~min}$ period of bile collection, $0.22 \mathrm{MBq}$ in $1 \mathrm{ml}$ of prepared HDL-[3 $\mathrm{H}] \mathrm{PC}$ containing $0.108 \mu \mathrm{mol} \mathrm{PC}$ was infused through a PE-50 catheter in the right jugular vein over a 15 -min period. This was followed by a 15 min intravenous infusion of a solution containing $35 \mathrm{~g} / \mathrm{l}$ bovine serum albumin (BSA, Sigma, Coger, Paris, France) in saline $(9 \mathrm{~g} \mathrm{NaCl} / \mathrm{l})$ at a rate of $4 \mathrm{ml} / \mathrm{h}$. Bile flow was determined gravimetrically assuming a density of $1 \mathrm{~g} / \mathrm{ml}$. After $120 \mathrm{~min}$, rats were killed by puncture of the abdominal aorta. Livers were removed and stored in a $1 \mathrm{~mm}-\mathrm{NaHCO}_{3}$ buffer solution, $\mathrm{pH} 7.5$, at $4^{\circ}$ and then homogenized for subcellular fractionation.

\section{Preparation of $\left[{ }^{3} H\right]$ phosphatidylcholine- $H D L$}

$\left[{ }^{3} \mathrm{H}\right] \mathrm{PC}-\mathrm{HDL}$ was prepared as previously described (Portal et al. 1993). Plasma (23 ml) was collected from four feed-deprived $(16 \mathrm{~h})$ donor rats, and HDL were isolated by 
Table 1. Composition of the diets $(\mathrm{g} / \mathrm{kg})$

\begin{tabular}{|c|c|c|c|c|}
\hline Diet... & $\mathrm{C}$ & C-TG & NPLE & PLE \\
\hline \multicolumn{5}{|l|}{ Ingredients } \\
\hline Casein* & 240 & 240 & 240 & 240 \\
\hline Sunfiower-seed oil $\dagger$ & 40 & 200 & - & - \\
\hline Semi-purified soyabean lecithin & - & - & 200 & - \\
\hline Purified soyabean lecithin & - & - & - & 200 \\
\hline Starch* & 240 & 140 & 140 & 140 \\
\hline Sucrose* & 183 & 123 & 123 & 123 \\
\hline Cellulose* & 40 & 40 & 40 & 40 \\
\hline Vitamin mixture*g & 10 & 10 & 10 & 10 \\
\hline Minerals*\| & 47 & 47 & 47 & 47 \\
\hline Distilled water & 200 & 200 & 200 & 200 \\
\hline Energy content $(\mathrm{kJ} / \mathrm{g})$ & $12 \cdot 58$ & $16 \cdot 26$ & 15.72 & $15 \cdot 63$ \\
\hline
\end{tabular}

C, control diet (40 g lipid $/ \mathrm{kg})$; C-TG, control lipid-rich diet ( $200 \mathrm{~g}$ lipid $/ \mathrm{kg}) ;$ NPLE, diet-enriched with $200 \mathrm{~g}$ semi-purified lecithin $/ \mathrm{kg}$; PLE, diet enriched with $200 \mathrm{~g}$ purified lecithin $/ \mathrm{kg}$.

* Provided by UAR, Villemoisson-sur-Orge, France.

$\dagger$ Lesieur, Paris, France.

\$ Lucas Meyer, Chelles, 77645 France.

$\S$ The vitamin mixture (UAR 200) provided the following (mg/ $\mathrm{kg}$ diet): retinol 12, cholecalciferol $0 \cdot 125$, thiamin 40 , riboflavin 30 , nicotinic acid 140 , pyridoxine 20 , pyridoxal 300 , cyanocobalamin $0 \cdot 1$, ascorbic acid 1600 , $\alpha$-tocopherol 340, menadione 80 , calcium pantothenate 200 , choline 2720 , pteroylmonoglutamic acid $10, p$ aminobenzoic acid 100 , biotin 0.6 .

li The salt mixture (UAR B205) provided the following (g/kg diet): $\mathrm{Ca} 4 \cdot 0, \mathrm{~K} 2 \cdot 4, \mathrm{Na} \mathrm{1 \cdot 6,} \mathrm{Mg} \mathrm{0} \cdot 4, \mathrm{Fe} 0 \cdot 12, \mathrm{Mn}$ $0.032, \mathrm{Cu} 0.005, \mathrm{Zn} 0.018$, Co 0.0004, I 0.002.

Table 2. Lipid and fatty acid composition of the diets

\begin{tabular}{|c|c|c|c|c|}
\hline Diet... & $\mathrm{C}$ & C-TG & NPLE & PLE \\
\hline \multicolumn{5}{|c|}{ Fatty acids (mol/100 mol fatty acids) } \\
\hline $16: 0$ & 5.6 & $5 \cdot 6$ & $14 \cdot 0$ & $14 \cdot 0$ \\
\hline $18: 0$ & $2 \cdot 2$ & $2 \cdot 2$ & $4 \cdot 0$ & $4 \cdot 0$ \\
\hline $18: 1$ & $25 \cdot 1$ & $25 \cdot 1$ & $11 \cdot 0$ & 11.0 \\
\hline $18: 2$ & $66 \cdot 2$ & $66 \cdot 2$ & $64 \cdot 0$ & $64 \cdot 0$ \\
\hline $18: 3$ & - & - & 7.0 & $7 \cdot 0$ \\
\hline Others & 0.9 & 0.9 & - & - \\
\hline \multicolumn{5}{|l|}{$\begin{array}{l}\text { Phospholipid classes } \\
\text { (mol/100 mol phospholipids) }\end{array}$} \\
\hline $\begin{array}{l}\text { Lysophosphatidycholine } \\
\text { f }\end{array}$ & - & - & $<3$ & $<3$ \\
\hline Phosphatidylcholine & - & - & 22 & 93 \\
\hline Phosphatidylinositol & - & - & 20 & $\operatorname{Tr}$ \\
\hline Phosphatidylserine & - & - & 2 & $\operatorname{Tr}$ \\
\hline Phosphatidylethanolamine & - & - & 23 & $\operatorname{Tr}$ \\
\hline Phosphatidic acid & - & - & 5 & $\operatorname{Tr}$ \\
\hline Sphingomyelin & - & - & - & - \\
\hline Soyabean sterols & - & - & 13 & $<0.5$ \\
\hline Other phospholipids & - & $\ldots$ & 9 & - \\
\hline Moisture and residual solvent & - & - & - & $<1.5$ \\
\hline
\end{tabular}

C, control diet $(40 \mathrm{~g}$ lipid $/ \mathrm{kg})$; C-TG, control lipid-rich diet $(200 \mathrm{~g}$ lipid $/ \mathrm{kg}) ;$ NPLE, diet enriched with $200 \mathrm{~g}$ semi-purified lecithin $/ \mathrm{kg} ;$ PLE, diet enriched with $200 \mathrm{~g}$ purified lecithin $/ \mathrm{kg} ; \mathrm{Tr}$, trace. 
ultracentrifugation and flotation at $120000 \mathrm{~g}$ for $22 \mathrm{~h}$ at $10^{\circ}$ in a sucrose solution of density $1.21 \mathrm{~g} / \mathrm{ml}$ according to the method of Hatch \& Less (1968). Ultracentrifugation was carried out in a Beckman L7 ultracentrifuge equipped with a fixed-angle rotor type 60Ti (Beckman, Gagny, France). The resulting HDL fraction was dialysed against saline for $2 \mathrm{~h}$ to remove sucrose.

HDL-PC were labelled by direct transfer of L $\alpha$-dipalmitoyl [choline-methyl${ }^{3} \mathrm{H}$ ]phosphatidylcholine (specific radioactivity: $1850 \mathrm{GBq} / \mathrm{mmol}$, NEN, Paris, France). The purity $(93 \%)$ of the commercial $\left[{ }^{3} \mathrm{H}\right] \mathrm{PC}$ solution was prechecked by TLC on silica gel (F 1500, Schleicher and Schüll, Dassel, Germany) using a chloroform-methanol-water (65:35:4, by vol.) mixture. Labelling of HDL was achieved by gently stirring HDL and $22.2 \mathrm{MBq}$ of the $\left[{ }^{3} \mathrm{H}\right] \mathrm{PC}$ aqueous solution for $18 \mathrm{~h}$ at $37^{\circ}$ (Martins et al. 1989; Tijburg et al. 1991). A $1 \mathrm{ml}$ portion of the prepared HDL- $\left[{ }^{3} \mathrm{H}\right] \mathrm{PC}$ contained $0.22 \mathrm{MBq}\left[{ }^{3} \mathrm{H}\right]$ and $0 \cdot 108 \mu \mathrm{mol} \mathrm{PC}$.

\section{Subcellular liver fractionation}

Livers were fractionated by sequential centrifugation and sucrose-gradient ultracentrifugation into two liver-cell plasma membrane fractions, one enriched in bile canalicular complexes (BCM) and the other containing mainly lateral sinusoidal membranes (PM) (Yousef et al. 1975). Microsomes were isolated by ultracentrifugation. The purity of the cellular fractions was estimated after determination of rotenone-insensitive NADPH ferrihaemoprotein reductase (EC 1.6.2.4), a microsomal marker (Sottocasa et al. 1967), leucine aminopeptidase (EC 3.4.11.1), a canalicular marker (Yousef \& Tuchweber, 1984) and 5'-nucleotidase (EC 3.1.3.5), a sinusoid marker (Yousef \& Tuchweber, 1984). The purity of the fractions was similar to that obtained in previous metabolic studies (Portal et al. 1993; Yousef et al. 1990). Enrichment of both leucine aminopeptidase and 5'nucleotidase was greater in BCM than in PM.

\section{Assays in the plasma, bile and liver membrane subfractions}

Total phospholipids in bile and membranes were analysed by measuring inorganic phosphate as described by Amic et al. (1972) after digestion in perchloric acid. Cholesterol in bile and membranes was measured by the method of Huang et al. (1961). Total and/or unesterified plasma cholesterol was assayed using the enzymic method of Lie et al. (1976). HDL-cholesterol was assayed by the method of Aufenanger et al. (1988). PC in plasma and HDL was analysed by the enzymic method of Takayama et al. (1977). Protein in HDL and liver membranes was determined by the method of Lowry et al. (1951). Bile acids were enzymically determined using $3 \alpha$-hydroxysteroid dehydrogenase (Sigma) (Domingo et al. 1972).

$\left[{ }^{3} \mathrm{H}\right]$ radioactivity in bile and liver membranes was counted in $10 \mathrm{ml}$ scintillation liquid (Beckman Ready Solv MP) using a Packard liquid scintillation counter (Tri Carb 1600 TR, Packard, Rungis, France) equipped with an external standard, and results were expressed in disintegrations/min. The distribution of the radioactivity on PC, lyso-PC and free choline in the bile was determined after separation by TLC using the conditions described above. The specific radioactivity of $\mathrm{PC}$ in bile and cellular organelles was calculated as the percentage of $\left[{ }^{3} \mathrm{H}\right]$ injected per nmol $\mathrm{PC}$.

\section{Tissue processing assay}

Pieces of liver, no more than $1 \mathrm{~mm}$ in size, were fixed for up to $6 \mathrm{~h}$ in $20 \mathrm{~g} / 1$ glutaraldehyde in phosphate-buffered saline $\left(0 \cdot 1 \mathrm{M}, \mathrm{pH} 7.4\right.$ at $\left.4^{\circ}\right)$. After several washes in the same buffer, samples were postfixed by $10 \mathrm{~g} / 1 \mathrm{OsO}_{4}$ in cacodylate buffer $(0 \cdot 1 \mathrm{M} \mathrm{pH} 7 \cdot 4)$, then dehydrated 


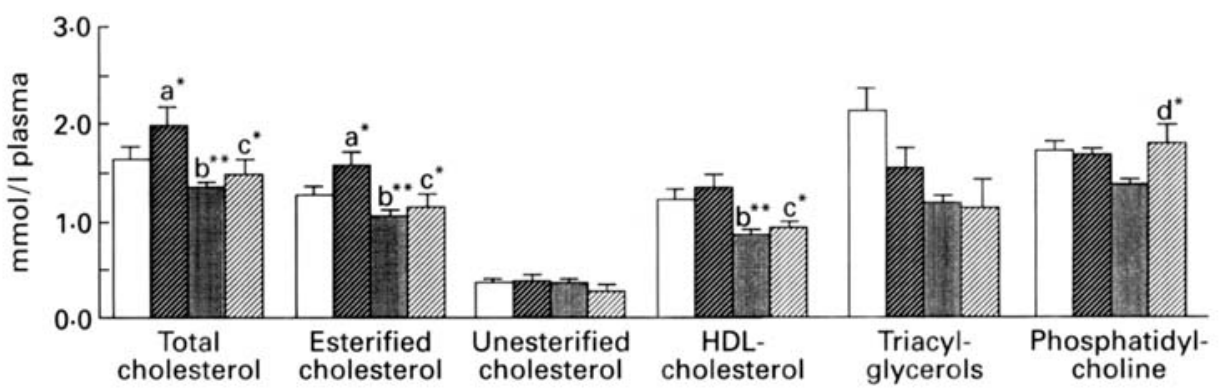

Fig. 1. Plasma cholesterol, triacyglycerol and phospholipid concentrations in rats fed on a low-fat control diet (C, $\square, n 7$ ), a high-fat control diet (C-TG, $n 7$ ), a diet containing $200 \mathrm{~g}$ semi-purified soyabean lecithin $/ \mathrm{kg}$ (NPLE, 圈, $n$ 8) or a diet containing $200 \mathrm{~g}$ purified soyabean lecithin $/ \mathrm{kg}$ (PLE, $\square, n$ 6). Values are means with their standard errors represented by vertical bars. Differences were assessed by ANOVA for factorial non-repeated values at a probability of $95 \%$ by Fisher's post-hoc least significant difference test or the Scheffe $F$ test. ${ }^{*}$ Significant difference as assessed by Fisher's test; ${ }^{* *}$ significant difference by both tests. ${ }^{\mathrm{a}} \mathrm{C} v, \mathrm{C}-\mathrm{TG} ;{ }^{\mathrm{b}} \mathrm{C}-\mathrm{TG} v$ NPLE; ${ }^{c}$ C-TG $v$. PLE; ${ }^{d}$ NPLE $v$. PLE.

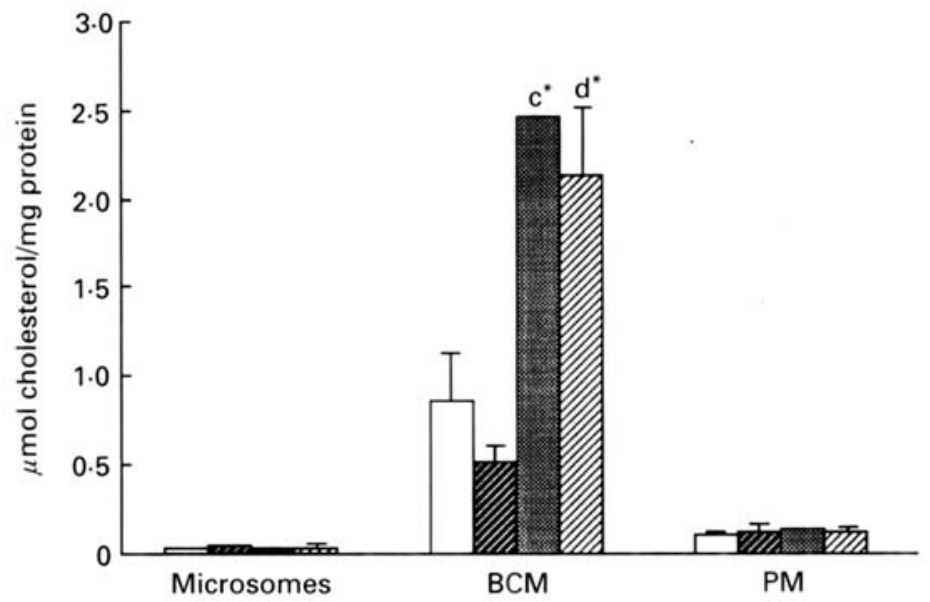

Fig. 2. Concentration of cholesterol in the microsomes, bile canalicular membranes (BCM) and total plasma membranes (PM) of rats fed on a low-fat control diet $(C, \square, n 7)$, a high-fat control diet (C-TG, 绿, $n 7$ ), a diet containing $200 \mathrm{~g}$ semi-purified soyabean lecithin $/ \mathrm{kg}$ (NPLE, 疄, $n$ 8) or a diet containing $200 \mathrm{~g}$ purified soyabean lecithin $/ \mathrm{kg}$ (PLE, $\oslash, n 6)$. Values are means with their standard errors represented by vertical bars. Differences were assessed for ANOVA for factorial non-repeated values at a probability of $95 \%$ by Fisher's post-hoc least significant difference test or the Scheffe $F$ test. * Significant difference as assessed by Fisher's test. ${ }^{\circ} \mathrm{C}$-TG $v$. PLE;

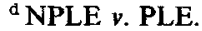

through ethanol and embedded in Epon 812 (Luft, 1961). Semi-thin sections $(2 \mu \mathrm{m}$ in thickness) were stained with toluidine blue.

\section{Statistical analysis}

Results are expressed as the arithmetical means of each group with their standard errors. We previously verified the homogeneity of the data in all conditions. Thus differences between groups were compared by using ANOVA for factorial experiments (Figs 1-3) or for repeated values (Fig. 4). The significant differences were determined by Fisher's posthoc least significant difference test and/or the Scheffe $F$ test at a probability value of $95 \%$. However, we restricted the statistical test to comparisons with only one variable $(\mathrm{C} v . \mathrm{C}$ TG; C-TG v. NPLE; C-TG v. PLE; NPLE v. PLE). 

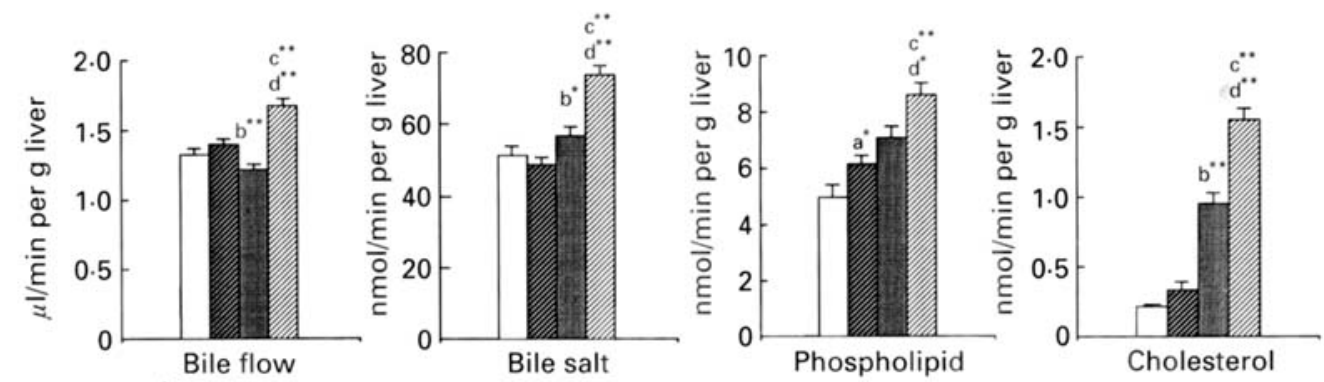

Fig. 3. Lipid composition of bile from rats fed on a low-fat control diet (C, $\square, n 7$ ), a high-fat control diet (C$\mathrm{TG}$, 四, $n$ 7), a diet containing $200 \mathrm{~g}$ semi-purified soyabean lethicin $/ \mathrm{kg}$ (NPLE, 圈, $n$ 8) or a diet containing $200 \mathrm{~g}$ purified soyabean lecithin $/ \mathrm{kg}$ (PLE, $\nabla, n 6$ ). Values are means with their standard errors represented by vertical bars. Differences were assessed by ANOVA for factorial non-repeated values at a probability of $95 \%$ by Fisher's post-hoc least significant difference test or the Scheffe $F$ test. ${ }^{*}$ Significant difference as assessed by Fisher's test; ** significant difference by both tests. ${ }^{a} \mathrm{C} v$. C-TG; ${ }^{\mathrm{b}} \mathrm{C}-\mathrm{TG} v$. NPLE; ${ }^{\mathrm{C}} \mathrm{C}-\mathrm{TG} v$. PLE; ${ }^{\mathrm{d}} \mathrm{NPLE} v$. PLE.

\section{RESULTS}

Plasma

As shown in Fig. 1, rats fed on the C-TG diet had significantly greater total cholesterol and esterified cholesterol compared with the control (low fat) group C. However, both NPLE and PLE lecithin diets led to a significant decrease of the total and esterified cholesterol compared with the C-TG group. This reduction was associated with a significant reduction in HDL-cholesterol. Lecithin-containing diets lowered plasma triacylglycerols nonsignificantly. Plasma PC was not significantly different between $\mathrm{C}$ and $\mathrm{C}-\mathrm{TG}$ groups, or between C-TG and PLE groups. However, there was a significant increase in plasma PC in the PLE group, compared with the NPLE group (Fig. 1).

\section{Liver}

Although both the NPLE and PLE diets caused a significant increase in cholesterol in the BCM compared with the C-TG diet, there were no changes in the cholesterol content of the microsomes or the PM (Fig. 2). On the other hand, phospholipid contents of the BCM microsomes and PM were not significantly affected by the different diets (about $0.6 \mu \mathrm{mol}$ phospholipid/mg protein in each subcellular fraction; results not shown).

\section{Bile}

Bile flow as well as bile salt, phospholipid and cholesterol secretion rates were significantly higher in the PLE group than in the C-TG group (Fig. 3). Bile salt and cholesterol outputs were significantly higher in the NPLE group than in the C-TG group. The level of radioactive $P C$ increased in the $C$ and $C-T G$ groups with the duration of the experiment, and reached a maximum between 60 and $75 \mathrm{~min}$; thereafter it remained constant until the end of the experiment (Fig. 4(a)). This plateau was at a significantly higher level in the C-TG group than in the C group. The PLE diet also significantly increased the secretion of radioactive $\mathrm{PC}$ as compared with $\mathrm{C}-\mathrm{TG}$, without reaching a maximum as in the C-TG group. The quantities of radioactive $\mathrm{PC}$ secreted in the bile were not significantly different between the NPLE and C-TG groups, from the beginning up to $75 \mathrm{~min}$ of experiment. Between 90 and 120 min the quantities of radiolabelled PC were significantly higher in rats consuming the NPLE diet than in those fed on the C-TG diet. However, there was no 

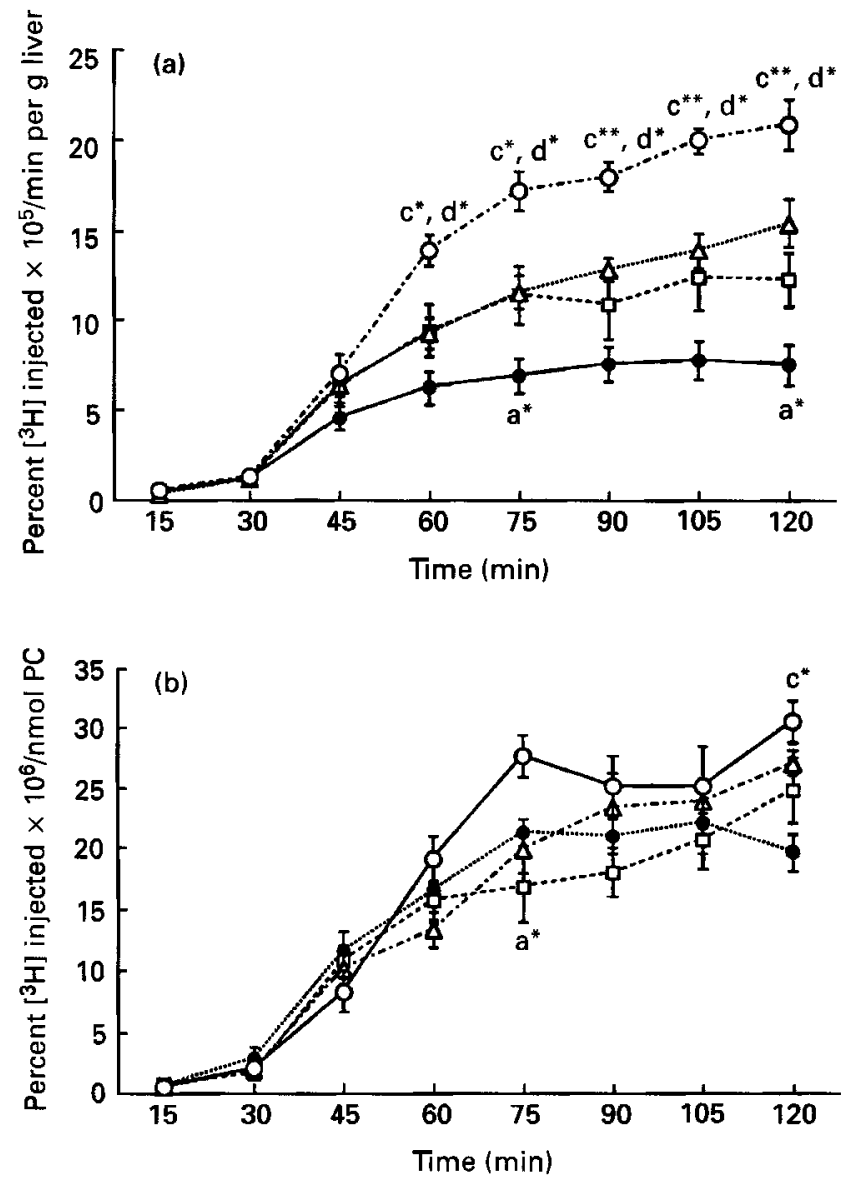

Fig. 4. (a) Quantities and (b) specific radioactivity of $\left[{ }^{3} \mathrm{H}\right]$ phosphatidylcholine $\left(\left[{ }^{3} \mathrm{H}\right] \mathrm{PC}\right)$ secreted in the bile of rats fed on a low-fat control diet (C, - - $n$ 7), a high-fat control diet (C-TG, $--\square--, n 7$ ), a diet containing $200 \mathrm{~g}$ semi-purified soyabean lecithin $/ \mathrm{kg}$ (NPLE, $--\Delta--, n 8)$ or a diet containing $200 \mathrm{~g}$ purified soyabean lecithin $/ \mathrm{kg}$ (PLE, - - O--, $n$ 6). Values are means with their standard errors represented by vertical bars. Differences were assessed by ANOVA for repeated values at a probability of $95 \%$ by Fisher's post-hoc least significant difference test or the Scheffe $F$ test. * Significant difference as assessed by Fisher's test; ${ }^{* *}$ significant difference by both tests. ${ }^{a} \mathrm{C} v$. C-TG; ${ }^{b} \mathrm{C}-\mathrm{TG} v$. NPLE; ${ }^{\mathrm{c} C-T G} v$. PLE; ${ }^{\mathrm{a}}$ NPLE $v$. PLE.

marked difference between the four groups in regard to the specific radioactivity of bile PC; the only significant differences occurred at $75 \mathrm{~min}$ between groups $\mathrm{C}$ and $\mathrm{C}-\mathrm{TG}$, and at 120 min between groups C-TG and PLE (Fig. 4(b)).

\section{Histological study of the liver}

The observations were carried out in order to determine eventual disturbances in the liver of the lecithin group. The histological structure was well preserved (Fig. 5). At the cellular level some observations can be made. In the lecithin group, at the periphery of the dilated bile canaliculi $(\uparrow)$, the pericanalicular areas appear deprived of mitochondria. Unstained small vacuoles $(\boldsymbol{\Lambda})$ are numerous and located in these areas; larger vacuoles $\left({ }^{*}\right)$ with a clear content are present facing the spaces of Disse. 


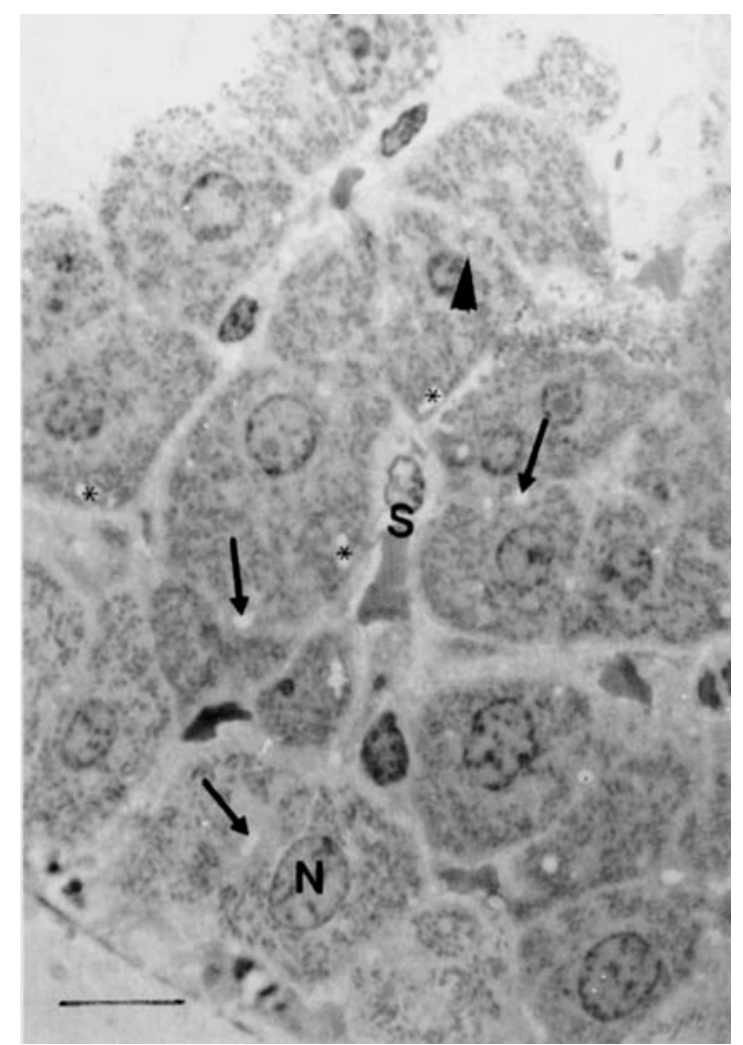

Fig. 5. Semi-thin sections, $2 \mu \mathrm{m}$ (toluidine blue) through rat livers. N, mucleus; S, sinusoid; *, large vacuoles; , small peribiliary vacuoles; $\uparrow$ bile canaliculi; bar, $100 \mu \mathrm{m}$.

\section{DISCUSSION}

Previous findings have shown that HDL is the main lipoprotein implicated in the physiological transport of lecithins (Martins et al. 1989) involving a plasma PC transfer protein (Pownall et al. 1991) and that the HDL fraction is largely implicated in the transport and/or exchange of cholesterol between tissues and plasma (Schwartz et al. 1993).

In the present experiment soyabean lecithin led to a significantly reduced level of esterified plasma cholesterol. HDL-cholesterol was significantly lower in both PLE and NPLE groups compared with the C-TG group. Our findings on plasma cholesterol partially corroborate those of Jimenez et al. (1990). These authors observed that polyunsaturated lecithin also induces a reduction in plasma cholesterol of hypercholesterolaemic rats by lowering VLDL-, intermediate-density-lipoprotein (IDL-) and LDL-cholesterol despite a rise in HDL-cholesterol. This enhancement of HDL-cholesterol by phospholipid-enriched diets in hypercholesterolaemic rats was confirmed by Iwata et al. (1993). The opposite effect of lecithin on HDL-cholesterol observed in these latter studies and in our work could be explained by differences in the experiments, which used hypercholesterolaemic and normolipidaemic rats respectively. In addition, the composition of soyabean lecithins is different according to their origin. Since our commercial semi-purified lecithin contained the same amounts of PC and phosphatidylethanolamine, part of the plasma-cholesterol- 
lowering effect observed with the semi-purified NPLE lecithin could have been due to dietary phosphatidylethanolamine which shows this effect in hypercholesterolaemic rats (Imaizumi et al. 1991). A possible cholesterol-lowering effect of other main components of commercial NPLE lecithin, such as phospholipids (phosphatidylinositol, phosphatidic acid) and vegetable sterols (phytosterols), might be considered.

Podrez et al. (1993) suggested that VLDL and bile salt productions are inversely correlated. Moreover, Robins et al. (1990) demonstrated that bile and HDL secretions by the liver are regulated by the bile salts. In the present experiment bile salt production was stimulated by lecithin feeding and this may represent a protective effect against atherogenic VLDL and LDL. Lecithin raised cholesterol in the bile canalicular vesicles. The abundance of small vacuoles formed at the periphery of the bile canaliculi suggest an enhanced traffic in this part of the cell. Such observations could be related to a significant increase in bile flow as well as in all biliary lipids. These results are in agreement with those of Rioux et al. (1994), obtained in normolipidaemic rats fed on diets enriched with commercial semipurified lecithin, and showing a higher level of all bile lipid components. In the present study the lecithin diets resulted in a significant rise of radiolabelled biliary PC originating from HDL-PC, compared with C-TG, while at each experimental time-point specific radioactivity of the bile $\mathrm{PC}$ did not show marked differences between the four groups. Thus, the higher amounts of total bile PC in the lecithin groups could result not only from a stimulation of $\left[{ }^{3} \mathrm{H}\right] \mathrm{HDL}-\mathrm{PC}$ uptake by the liver but also from enhanced release by hepatic microsomes of unlabelled neosynthesized or preformed PC. Our data show that the molar ratio of unesterified cholesterol to phospholipids in the bile was higher in the NPLE and PLE groups than in the C-TG group. This increase in both lecithin groups could not be correlated to the stable unesterified cholesterol: phospholipids ratio observed in the plasma of rats in all groups. Thus, lecithin could mobilize another source of bile cholesterol as plasma (HDL)-cholesterol, possibly from the preformed or newly synthesized hepatic microsomal cholesterol pool. This hypothesis is based on other results (Ide et al. 1994) showing that soyabean lecithin stimulates hepatic cholesterol biosynthesis.

Rioux et al. (1994) found no evidence of modification of the nature of PC fatty acids in the bile and liver plasma membranes, after lecithin administration, as could be explained by studies of Iwata et al. (1993). These authors proposed that the hypocholesterolaemic effect of lecithin was unrelated to the degree of polyunsaturation of lecithin fatty acids. Thus the cholesterol-lowering effect of lecithin could be linked to the hydrophilic nature of the lecithin head. However, such a hypothesis needs further investigation.

In conclusion, the specific cholesterol-lowering effect of dietary lecithin can be explained in part by a stimulation of uptake of a PC carrier-HDL by the liver. The stimulation results in higher amounts of bile lipids provided by both $\mathrm{HDL}$ and hepatic microsomal pools of $\mathrm{PC}$ and cholesterol.

This work was supported by a grant from the French and Canadian Ministeries of foreign affairs. Lecithin was graciously provided by Lucas Meyer Ltd. We wish to thank $\mathrm{Mr}$ Patrick Garzino for animal care.

\section{REFERENCES}

Amic, J., Lairon, D. \& Hauton, J. C. (1972). Technique de dosage automatique de l'orthophosphate de grande fiabilité (Automatic and accurate assay technique for orthophosphate). Clinica Chimica Acta 40, $107-114$.

Aufenanger, J., Haux, P., Weber, U. \& Kattermann, R. (1988). A specific method for the direct determination of lipoprotein cholesterol in electrophoretic patterns. Clinica Chimica Acta 177, 197-208.

Bravo, E. \& Cantafora, A. (1990). Hepatic uptake and processing of free cholesterol from different lipoproteins with and without sodium taurocholate administration. An in vivo study in the rat. Biochimica et Biophysica Acta 1045, 74-80. 
Chanussot, F., Lafont, H., Hauton, J., Tuchweber, B. \& Yousef, I. (1990). Studies on the origin of biliary phospholipid. Effect of dehydrocholic acid and cholic acid infusions on hepatic and biliary phospholipids. Biochemical Journal 270, 691-695.

Domingo, N., Amic, J. \& Hauton, J. (1972). Dosage automatique des sels biliaires conjugués de la bile par la $3 \alpha-$ hydroxystéroïde déshydrogénase (Automatic assay for conjugated bile salts in bile by an enzymic technique using 3 $\alpha$-hydroxysteroid dehydrogenase). Clinica Chimica Acta 37, 399-404.

Esnault-Dupuy, C., Chanussot, F., Lafont, H., Chabert, C. \& Hauton, J. (1987). The relationship between HDL-, LDL-, liposomes-free cholesterol, biliary cholesterol and bile salts in the rat. Biochimie 69, 45-52.

Halloran, L. G., Schwartz, C. C., Vlahcevic, Z. R., Nisman, R. M. \& Swell, L. (1978). Evidence for high-density lipoprotein free cholesterol as the primary precursor for bile-acid synthesis in man. Surgery 84, 1-7.

Hatch, F. T. \& Less, R. S. (1968). Practical methods for plasma lipoprotein analysis. Advances in Lipid Research 6, 1-68.

Huang, C., Chen, C. P., Wefler, V. \& Raftery, A. (1961). A stable reagent for the Lieberman-Burchard reaction, application to rapid serum cholesterol determination. Analytical Chemistry 33, 1405-1407.

Ide, T., Murata, M. \& Sunada, Y. (1994). Triacylglycerol and fatty acid synthesis in hepatocytes in suspension isolated from rats fed soybean phospholipid. Bioscience, Biotechnology, and Biochemistry 58, 699-702.

Imaizumi, K., Sekihara, K. \& Sugano, M. (1991). Hypocholesterolemic action of dietary phosphatidylethanolamine in rats sensitive to exogenous cholesterol. Journal of Nutritional Biochemistry 2, 251-254.

Iwata, T., Hoshi, S., Takehisa, F., Tsutsumi, K., Furukawa, Y.\& Kimura, S. (1992). The effect of dietary safflower phospholipid and soybean phospholipid on plasma and liver lipids in rats fed a hypercholesterolemic diet. Journal of Nutritional Science and Vitaminology 38, 471-479.

Iwata, T., Kimura, Y., Tsutsumi, K., Furukawa, Y. \& Kimura, S. (1993). The effect of various phospholipids on plasma lipoproteins and liver lipids in hypercholesterolemic rats. Journal of Nutritional Science and Vitaminology $39,63-71$.

Jimenez, M. A., Scarino, M. L., Vignolini, F. \& Mengheri, E. (1990). Evidence that polyunsaturated lecithin induces a reduction in plasma cholesterol level and favorable changes in lipoprotein composition in hypercholesterolemic rats. Journal of Nutrition 120, 659-667.

Knuiman, J. T., Beynen, A. C. \& Katan, M. B. (1989). Lecithin intake and serum cholesterol. American Journal of Clinical Nutrition 49, 266-268.

Lie, R. F., Schmitz, J. M., Pierre, K. J. \& Gochman, N. (1976). Cholesterol oxidase-based determination by continuous flow analysis of total and free cholesterol in serum. Clinical Chemistry 22, 1627.

Lowry, O. H., Rosebrough, N. F., Farr, A. L. \& Randall, R. J. (1951). Protein measurement with the Folin phenol reagent. Journal of Biological Chemistry 193, 265-275.

Luft, J. H. (1961). Improvements in epoxy resin embedding methods. Journal of Biophysical and Biochemical Cytology 9, 409.

Martins, I. J., Lenzo, N. P. \& Redgrave, T. G. (1989). Phosphatidylcholine metabolism after transfer from lipid emulsions injected intravenously in rats. Implications for high-density lipoprotein metabolism. Biochimica et Biophysica Acta 1005, 217-224.

Podrez, E. A., Kosykh, V. A., Lakeev, Y. V., Kosenkov, E. I., Mambetisaeva, E. T., Repin, V. S., Smirnov, V. N. \& Miettinen, T. A. (1993). Bile acid and very low density lipoprotein production by cultured hepatocytes from hypo- or hyperresponsive rabbits fed cholesterol. Lipids 28, 709-713.

Portal, I., Clerc, T., Sbarra, V., Portugal, H., Pauli, A. M., Lafont, H., Tuchweber, B., Yousef, I. \& Chanussot, F. (1993). Importance of high-density lipoprotein-phosphatidylcholine in secretion of phospholipid and cholesterol in bile. American Journal of Physiology 264, G1052-G1056.

Pownall, H. J., Hickson-Bick, D. \& Massey, J. B. (1991). Effects of hydrophobicity on turnover of plasma high density lipoproteins labeled with phosphatidylcholine ethers in the rat. Journal of Lipid Research 32, 793-800.

Rioux, F., Perea, A., Yousef, I. M., Levy, E., Malli, L., Carrillo, M. C. \& Tuchweber, B. (1994). Short-term feeding of a diet enriched in phospholipids increases bile formation and the bile acid transport maximum in rats. Biochimica et Biophysica Acta 1214, 193-202.

Rivabene, R., Cantafora, A., Yan, C. C., Castellano, F., Bruscalupi, G. \& Bravo, E. (1992). Effect of HDL1 infusion on biliary secretion in perfused rat liver. Bioscience Reports 12, 425-432.

Robins, S. J., Fasulo, J. M. \& Patton, G. M. (1990). Effect of bile salt on phosphatidylcholine composition and secretion of hepatic high-density lipoproteins. American Journal of Physiology 259, G205 G211.

Schwartz, C. C., Zech, L. A., Van den Broek, J. \& Cooper, P. S. (1993). Cholesterol kinetics in subjects with bile fistula. Positive relationship between size of the bile acid precursor pool and bile acid synthetic rate. Journal of Clinical Investigation 91, 923-938.

Sottocasa, G. L., Kuylenstierna, B., Ernster, L. \& Bergstrand, A. (1967). An electron transport system associated with the outer membrane of liver mitochondria. Journal of Cell Biology 32, 415-438.

Takayama, M., Itoh, S., Nagasaki, T. \& Tanimizu, I. (1977). A new enzymatic method for choline containing phospholipids. Clinica Chimica Acta 79, 93-98.

Tijburg, L. B. M., Samborski, R. W. \& Vance, D. E. (1991). Evidence that remodeling of the fatty acids of phosphatidylcholine is regulated in isolated rat hepatocytes and involves both the sn-1 and sn-2 positions. Biochimica et Biophysica Acta 1085, 184-190.

Tompkins, R. K. \& Parkin, L. G. (1980). Effects of long-term ingestion of soya phospholipids on serum lipids in humans. American Journal of Surgery 140, 360-364. 
Williams, K. J., Werth, V. P. \& Wolf, J. A. (1984). Intravenously administered lecithin liposomes: a synthetic antiatherogenic lipid particle. Perspectives in Biology and Medicine 27, 417-431.

Yousef, I. M., Bloxham, D. L., Philipps, M. J. \& Fisher, M. M. (1975). Liver cell plasma membrane lipids and the origin of biliary phospholipid. Canadian Journal of Biochemistry 53, 989-997.

Yousef, I. M., Mignault, D., Weber, A. M. \& Tuchweber, B. (1990). Influence of dehydrocholic acid on the secretion of biliary phospholipid. Digestion 45, 40-51.

Yousef, I. M. \& Tuchweber, B. (1984). Effect of lithocholic acid on cholesterol synthesis and transport in the rat liver. Biochimica et Biophysica Acta 796, 336-344. 